\title{
Hereditary oral squamous cell carcinoma associated with CDKN2A germline mutation: a case report
}

\author{
Ah-Reum Jeong ${ }^{1}$, Kimberly Forbes ${ }^{1}$, Ryan K. Orosco ${ }^{2,3}$ and Ezra E. W. Cohen 1,3*
}

\begin{abstract}
Background: Germline CDKN2A mutations are a well-known cause of familial atypical multiple mole melanoma (OMIM \#155601) and melanoma-pancreatic cancer syndrome (OMIM \#606719). Increased risk of head and neck squamous cell carcinoma (HNSCC), particularly oral squamous cell carcinoma (OSCC) in those with germline CDKN2A mutations, has been described. However, screening for HNSCC is not a routine practice in patients with CDKN2A germline mutations and these mutations are not a conventional test for HNSCC patients without obvious risk factors.

Case presentation: We describe a female with no smoking history who developed oral squamous cell carcinoma at age 39 and had a complex clinical course of recurrent multifocal squamous cell carcinoma (SCC) and carcinoma in situ of the oral cavity and oropharynx. Detailed family history demonstrated that her mother was diagnosed with OSCC and melanoma in her $40 \mathrm{~s}$, and her maternal grandfather was diagnosed with metastatic melanoma in his $40 \mathrm{~s}$. Genetic testing of the patient and her mother revealed CDKN2A c.301G>T mutation. She was referred to genetic counseling as well as to dermatology, gastroenterology, and neurology for cancer surveillance. She was treated with resections and has no evidence of disease 3 years after diagnosis.

Conclusions: We report a family with a CDKN2A c.301 G>T mutation who also have significant history of OSCC, adding to the growing body of literature suggesting increased risk of HNSCC, particularly OSCC, in CDKN2A germline mutation carriers. It is important to consider CDKN2A mutation testing in familial HNSCC and young patients without obvious risk factors. Moreover, surveillance for HNSCC should be routine practice in those with a CDKN2A germline mutation.
\end{abstract}

Keywords: CDKN2A germline mutation, Familial atypical multiple moles melanoma, Head and neck squamous cell cancer, Oral squamous cell cancer, Case report

\footnotetext{
*Correspondence: ecohen@health.ucsd.edu

${ }^{1}$ Division of Hematology and Oncology, Department of Medicine,

University of California San Diego, 3855 Health Sciences Drive, La Jolla, CA 92093-0960, USA

Full list of author information is available at the end of the article
} permits use, sharing, adaptation, distribution and reproduction in any medium or format, as long as you give appropriate credit to the original author(s) and the source, provide a link to the Creative Commons licence, and indicate if changes were made. The images or other third party material in this article are included in the article's Creative Commons licence, unless indicated otherwise in a credit line to the material. If material is not included in the article's Creative Commons licence and your intended use is not permitted by statutory regulation or exceeds the permitted use, you will need to obtain permission directly from the copyright holder. To view a copy of this licence, visit http://creativecommons.org/licenses/by/4.0/. The Creative Commons Public Domain Dedication waiver (http://creativeco mmons.org/publicdomain/zero/1.0/) applies to the data made available in this article, unless otherwise stated in a credit line to the data. 
Graphical abstract

\section{HEREDITARY ORAL SQUAMOUS CELL CARCINOMA ASSOCIATED WITH CDKN2A GERMLINE MUTATION: A CASE REPORT}

Jeong AR, Forbes K, Orosco RK, Cohen EEW
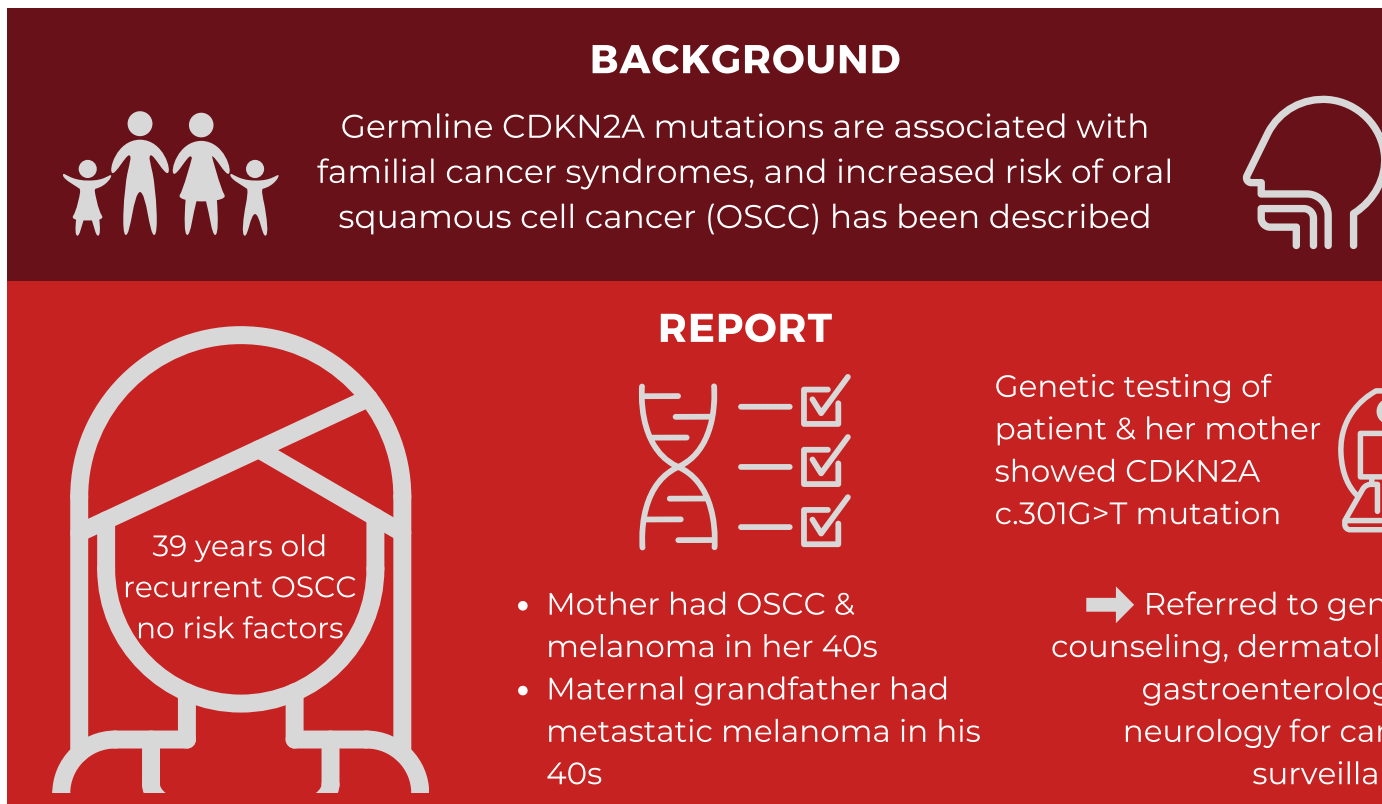

REPORT

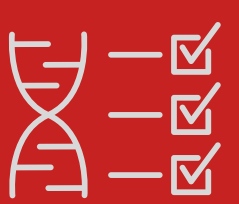

Genetic testing of

patient \& her mother

showed CDKN2A

c.301G > T mutation

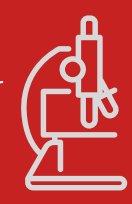

- Mother had OSCC \& melanoma in her 40 s

$\Rightarrow$ Referred to genetic

Maternal grandfather had counseling, dermatology,

metastatic melanoma in his gastroenterology, \& $40 \mathrm{~s}$ neurology for cancer surveillance

It is important to consider CDKN2A mutation testing in familial HNSCC and young patients without obvious risk factors; surveillance for HNSCC should be routine practice in those with a CDKN2A germline mutation.

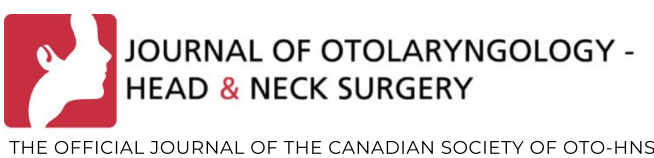

\section{Background}

Cyclin dependent kinase inhibitor 2A (CDKN2A; OMIM 600160), located on 9p21.3, encodes proteins critical in cell cycle regulation. Through alternative reading frames, $C D K N 2 A$ produces 2 major proteins: p16(INK4a), the cyclin dependent kinase (CDK) inhibitor, and p14(ARF), p53 stabilizer [1]. Germline, (inherited, in contrast to somatic or acquired), mutations of $C D K N 2 A$ are the most common cause of inherited susceptibility to melanoma and is implicated in 25-40\% of patients with familial atypical multiple mole melanoma (FAMMM; OMIM \#155601) [2]. It is also associated with melanoma-pancreatic cancer syndrome (OMIM \#606719), with an incidence of up to $60 \%$ depending on the type of mutation
[2, 3]. Higher than expected frequencies of other types of cancers, such as head and neck squamous cell carcinoma (HNSCC), neural system tumors, GI cancer, breast cancer, and lung adenocarcinoma are reported in association with CDKN2A mutations, depending on the protein (either p14 or p16) affected [4]. However, there is no clear consensus on screening for cancers other than melanoma and pancreatic cancer. It is thus important to understand the association between CDKN2A mutation and development of non-melanoma and non-pancreatic cancer as patients should be appropriately counseled and monitored.

Here, we report a family with CDKN2A c.301G>T mutation who had multiple oral squamous cell cancers 
Table 1 Summary of treatment history and pathology results

\begin{tabular}{lll}
\hline Months from diagnosis & Treatment & Pathology \\
\hline 0 & R partial glossectomy & Primary oral SCC \\
1 & R partial glossectomy & Carcinoma in situ and severe dysplasia \\
11 & R partial glossectomy & 2 areas of carcinoma in situ \\
15 & Pembrolizumab (off label) & \\
17 & R partial glossectomy and oropharynx resection & high grade dysplasia and carcinoma in situ \\
19 & Base of tongue resection & Mild dysplasia \\
\hline
\end{tabular}

(OSCC) and melanoma. We review the growing body of literature of HNSCC in patients with CDKN2A mutations and propose that $C D K N 2 A$ be a differential upon testing strategy in familial HNSCC, and that patients with $C D K N 2 A$ mutation should be counseled regarding the risks of HNSCC.

\section{Case presentation}

The patient is a 40-year-old female who was referred to our center for evaluation and treatment of recurrent Stage I (cT1N0M0) right tongue squamous cell carcinoma (SCC). The treatment history and pathology results are summarized in Table 1.

She was diagnosed at age of 39 , when she presented with pain and ulcer of her right tongue. Biopsy of the lesion demonstrated dyskeratosis but no malignancy. She experienced progressive pain and ulceration which led to right partial glossectomy. Pathology demonstrated SCC with positive anterior margin and dysplasia at the inferior margin. The tumor stained positively for $\mathrm{p} 16$ by immunohistochemistry. Subsequent positron emission tomography (PET)/computed tomography (CT) demonstrated $1.2 \mathrm{~cm}, \mathrm{PET}$-avid left thyroid nodule however no hypermetabolic lesions of the oral cavity or the cervical lymph nodes were demonstrated. Fine needle aspiration (FNA) of the thyroid nodule showed papillary thyroid carcinoma. She underwent total thyroidectomy, central neck dissection, and revision of her right partial glossectomy 5 weeks after her initial surgery. The pathology of her thyroid tissue showed Stage I (pT3bN1aM0) papillary thyroid carcinoma (PTC). Pathology of her R tongue resection showed severe dysplasia and carcinoma in situ. She received adjuvant radioactive iodine and is currently in remission from her PTC. Subsequently, she developed multiple recurrent oral squamous cell carcinoma in situ (and high grade dysplasia) despite resection. She was treated with pembrolizumab off-label at the outside clinic. When she developed a new high-grade dysplasia of the tongue, she was referred to our center for further management.
Her other medical history included post-thyroidectomy hypothyroidism and temporary hypoparathyroidism. As a result of immunotherapy, she developed type 1 diabetes mellitus. Her medications were calcitriol, levothyroxine, and insulin. Her mother, who is a life-long non-smoker, also has a history of early-stage melanoma at age 48 , and tongue cancer at age 50 (Fig. 1). Her maternal grandfather was diagnosed with metastatic melanoma in his $40 \mathrm{~s}$. There is no history of cancers on the paternal side. She denies any history of heavy alcohol use, smoking, or recreational drug use.

On evaluation, there was right tongue mucosal lesion that extended back to the oropharynx and a biopsy showed high grade dysplasia. She underwent a right partial glossectomy and right oropharynx resection. That specimen had carcinoma in situ, no invasive carcinoma, and two margins had mild dysplasia. Two months later, she was taken for a wide excision of the tongue base mucosa which was negative for dysplasia. Germline testing of 156 cancer related genes showed CDKN2A (c.301G $>$ T) pathogenic mutation. Her mother and two siblings were also tested and her mother and sister were found to have the same germline mutation. Human Papilloma Virus (HPV) genotypes 16 and 18 DNA of the tongue biopsy specimen by polymerase chain reaction (PCR) were negative. She has now been without recurrence of SCC or carcinoma in situ for 18 months. She was referred to dermatology, gastroenterology, and neuro oncology for melanoma, pancreatic cancer, and brain tumor screening (Fig. 2).

\section{Discussion}

We describe a case of a young female, life-long nonsmoker, who presents with recurrent tongue SCC. Her case is unusual as she did not have significant risk factors for HNSCC such as tobacco use or alcohol use. Despite curative resection, she had multiple recurrent dysplasia and carcinoma in situ both at the resection margin and other parts of the tongue. Upon obtaining further history, her maternal family members had significant history of melanoma and HNSCC (Fig. 1). Patient's mother, also a 


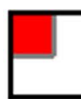

Tongue SCC

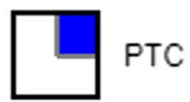

PTC
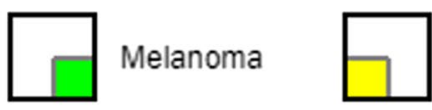

+: CDKN2A mutation

Swedish

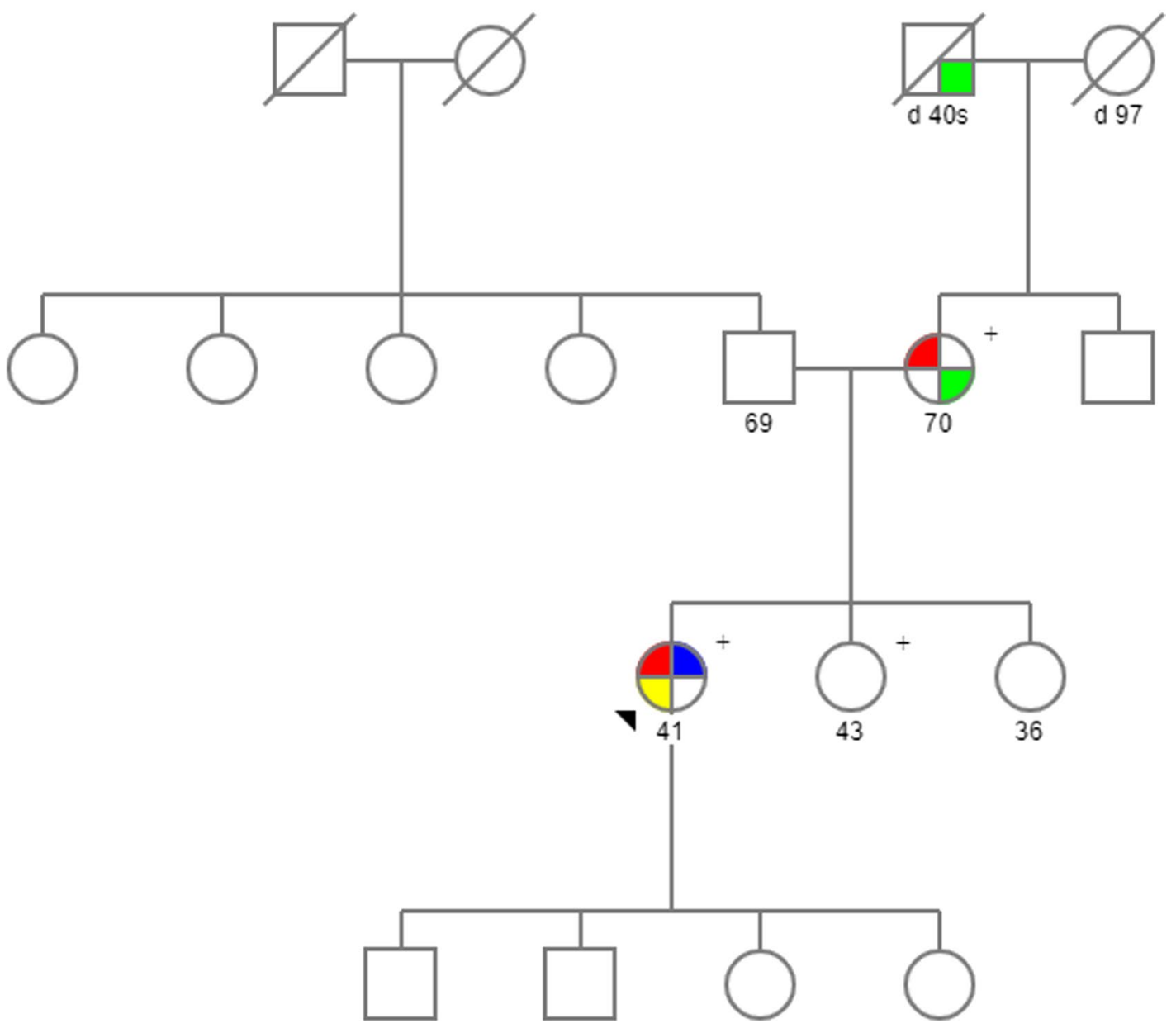

Fig. 1 Pedigree. PTC, papillary thyroid carcinoma; SCC, squamous cell carcinoma

life-long non-smoker, was diagnosed with melanoma at age 48 and tongue cancer at age 50 . The proband's maternal grandfather had metastatic melanoma in his late $40 \mathrm{~s}$. Genetic testing of both the proband and her mother revealed $C D K N 2 A$ (c.301G $>\mathrm{T})$ mutation.

$C D K N 2 A$ (c.301G>T) mutation results in substitution of glycine with tryptophan at codon 101 (G101W) of the p16(INK4a) protein and replacement of arginine with leucine at codon 115 of the $\mathrm{p} 14(\mathrm{ARF})$ protein. This variant is one of the most common types of CDKN2A mutations reported in Europe and North America [2]. It is particularly common in Italian families which this patient's maternal ancestry traces back to. This mutant protein demonstrates significantly decreased binding of p16 to CDK4 and CDK6 [5].

The importance of $\mathrm{p} 16$ protein in the pathogenesis of various cancers have been well described. The p16 protein inhibits CDK4 and CDK6 and regulates cell cycle at the G1-S checkpoint [6]. Somatic mutations of CDKN2A are found in various sporadic forms of cancers. In 


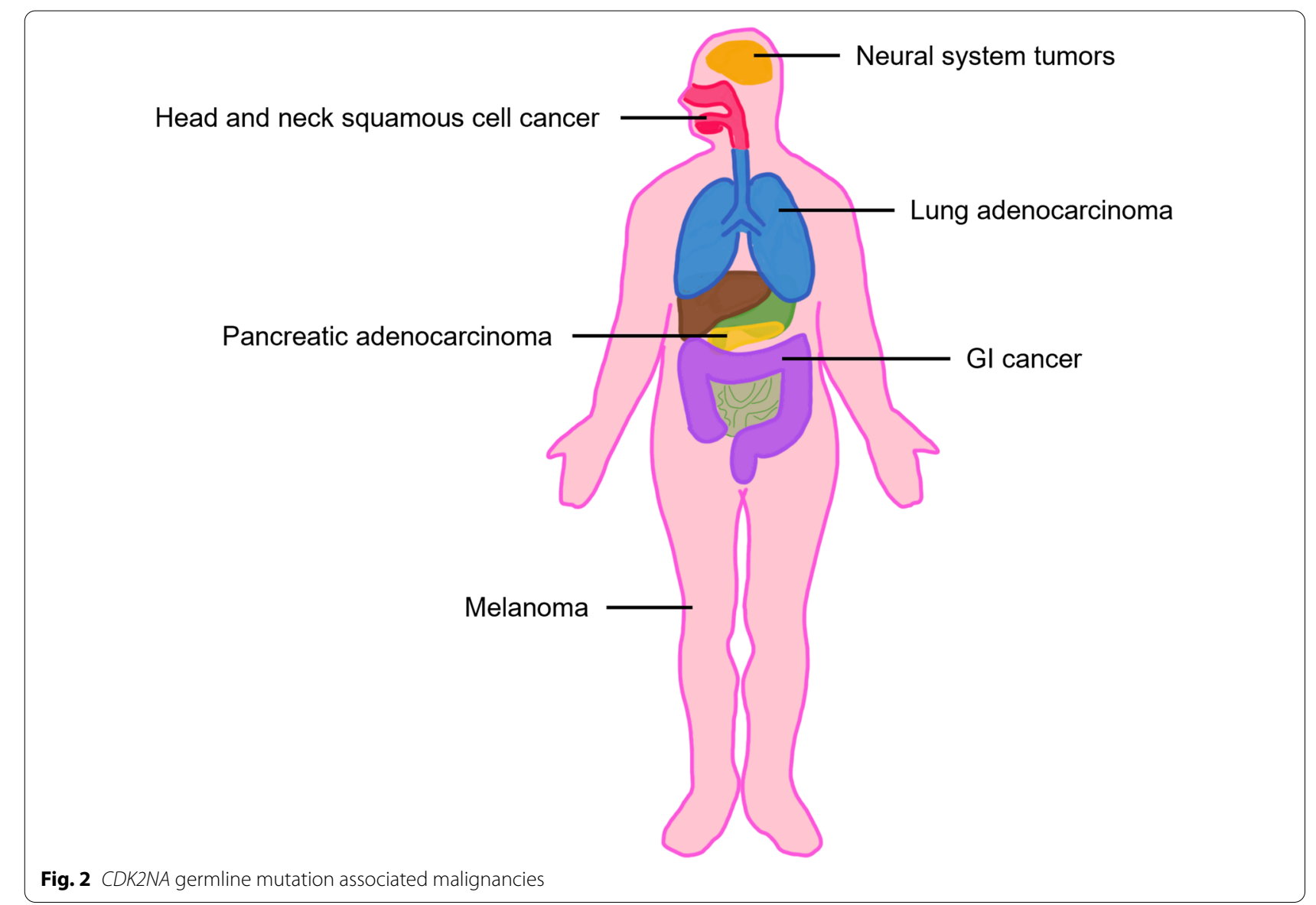

HPV-negative HNSCC, somatic mutations of the p16/ CDK-cyclin-D/retinoblastoma $(\mathrm{Rb})$ pathway is one of the most common early mutations observed, reported in approximately $20 \%$ of cases $[7,8]$. In HPV positive HNSCC, the oncogene E7 inhibits Rb protein which leads to epigenetic de-silencing of $C D K N 2 A$ gene, and subsequent increased expression of p16INK4a [9].

Given its important function in tumorigenesis, loss of the wild type $C D K N 2 A$ allele in those with a germline mutation is likely a key event in development of HNSCC. Patient who is a carrier of abnormal CDKN2A gene is asymptomatic until the normal $C D K N 2 A$ gene acquires a loss-of-function mutation (also termed loss of heterozygosity). Loss of heterozygosity is reported in all HNSCC cases with a germline CDKN2A mutation, in those who were tested [10-15]. Thus, patients who acquire mutation of the wild type CDKN2A gene by environmental or secondary factors may be at increased risk of developing HNSCC. In our patient, not enough tissue was available for next generation sequencing (NGS), thus loss of heterozygosity was not able to be demonstrated.

Interestingly, our patient demonstrated $\mathrm{p} 16$ positivity by immunohistochemistry (IHC). None of the reported cases of HNSCC in those with CDKN2A germline mutation demonstrated p16 positivity: either the patients had negative p16 expression by IHC $[12,13]$. or patients whose tumor was p16 negative were selected for study [10]. This finding may be expected as $C D K N 2 A$ codes for the p16 protein, and mutation in CDKN2A could result in loss of expression. Furthermore, p16 expression by IHC is a screening marker for HPV related HNSCC. Notably, G101W mutant p16 were shown to localize to nucleus in vitro and in melanocytes $[16,17]$. In melanoma, mutant p16 expression decreased with more advanced stages of disease [16]. Therefore, it is not surprising that p16 was detected by IHC in this early stage tongue cancer. HPV genotype 16 and 18 DNA were negative ruling out an HPV driven process. It is important to consider $C D K N 2 A$ mutation in familial HNSCC even if p16 is positive by IHC and should be confirmed by PCR testing.

CDKN2A germline mutations are implicated in FAMMM. Although there is clear association with increased risk of cutaneous melanoma, the risk of mucosal melanoma is less well defined. It is also associated with development of hereditary pancreatic cancer syndromes $[4,18]$, and surveillance detected pancreatic 
Table 2 Summary of reported cases of HNSCC with confirmed underlying CDKN2A germline mutation

\begin{tabular}{|c|c|c|c|c|c|}
\hline References & Patient ID ${ }^{a}$ & Mutation & LOH & Type of HNSCC & p16 IHC \\
\hline Whelan et al.[26] & IV-1 & G101W & N/A & OSCC (tongue) & N/A \\
\hline \multirow[t]{2}{*}{ Sun et al.[25] } & $\mid-1$ & c.G159C (M53I) & N/A & oscC & N/A \\
\hline & || $\mid-1$ & c.G159C (M53I) & N/A & oscC & N/A \\
\hline Yarbrough et al. [14] & Proband's niece & $\mathrm{P} 16(\Delta 96-99)$ & Yes & HNSCC & N/A \\
\hline Della Torre et al. [24] & || $\mid-17(2587)$ & $\mathrm{P} 48 \mathrm{~T}$ & N/A & OsCC & N/A \\
\hline \multirow[t]{3}{*}{ Yu et al. [15] } & $\|-A$ & c.G260C (R87P) & Yes & OSCC (tongue) & N/A \\
\hline & $\|-D$ & c.G260C (R87P) & Yes & HNSCC & N/A \\
\hline & 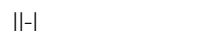 & c.G260C (R87P) & Yes & HNSCC & N/A \\
\hline Schneider-Stock et al. [12] & Proband & P16-Leiden & Yes & oscc & Neg \\
\hline \multirow[t]{2}{*}{ Oldenburg et al. [11] } & 36 (EMC 13769) & p16-Leiden & N/A & OSCC (tongue) & N/A \\
\hline & 48 (EMC 13769) & p16-Leiden & Yes & oscC & Neg \\
\hline Vinarsky et al. [13] & Ila & c.G302T (G101W) & Yes & OSCC (tongue) & N/A \\
\hline \multirow[t]{2}{*}{ Cabanillas et al. [23] } & || $\mid-15$ & c.106delG & N/A & OSCC (hard palate) & N/A \\
\hline & || $\mid-16$ & c.106delG & N/A & Hypopharyngeal SCC & N/A \\
\hline \multirow[t]{2}{*}{ Fostira et al. [10] } & OT-10 & c.G71C & Yes & OSCC & Neg \\
\hline & OT-14 & c.G71C & Yes & OSCC & Neg \\
\hline Chan et al. [27] & Proband & Deletion CDKN2A-CDKN2B & Yes & Laryngeal SCC & Neg \\
\hline
\end{tabular}

Those patients who have confirmed mutation by sequencing or obligate carriers are included

${ }^{\text {a }}$ As published in the original article

HNSCC, head and neck squamous cell carcinoma; IHC, immunohistochemistry; LOH, loss of heterozygosity; N/A, not available; Neg, negative; OSCC, oral squamous cell carcinoma; SCC, squamous cell carcinoma

cancer was more likely to be resectable and patients had higher overall survival rate at 5 years compared to historical control [19]. Due to the increased risk of melanoma and pancreatic cancer, current guidelines suggest total body skin exams, including oral mucosa, genital area, and nails at 3-6 month intervals starting late adolescence [20] and annual screening for pancreatic cancer starting at age 40 with magnetic resonance imaging (MRI) and endoscopic ultrasonography (EUS) [21]. Increased risk of neural systems tumor (melanoma-astrocytoma syndrome; OMIM \#155755) is also reported [18, 22], although there is no formal screening guideline for astrocytoma. In contrast, CDKN2A germline mutation as a cause of familial HNSCC is not widely accepted, and patients are not screened for HNSCC. There is a growing body of evidence that families with germline CDKN2A mutations are at increased risk of HNSCC, particularly oral SCC (Table 2) [10-15, 23-27].

In a population-based study of Icelandic patients with melanoma and controls, Goldstein and colleagues [28] identified an Icelandic founder mutation G89D with allelic frequency of $0.7 \%$ among melanoma patients. The Icelandic patients with melanoma who had G89D mutation also had familial relative risk for HNSCC of 4.84 $(p=0.016)$.

$C D K N 2 A$ mutation was also demonstrated in a prospective group of OSCC patients. Fostira and colleagues
[10] analyzed patients who were less than 50 years old and with a history of HPV negative OSCC for any predisposing germline mutations. Among 30 patients who were prospectively enrolled, 4 patients were found to have potential pathogenic germline mutations. Two of the 4 unrelated patients had $C D K N 2 A$ c. $71 \mathrm{G}>\mathrm{C}$ mutation and both exhibited $\mathrm{LOH}$ on the tumor sample testing. Both had significant smoking history prior to diagnosis.

In addition to the increased risk of melanoma, pancreatic cancer, and neural systems tumor, various cancers have been reported in patients with germline CDKN2A mutation. These include breast adenocarcinoma [4, 2934], lung adenocarcinoma [4, 33, 35], sarcoma [35-37], and neurofibroma [22, 31, 34, 38-40], and the available literature is summarized in Table 3.

Although limited by the small number of cases, this report adds to the growing body of evidence that $C D K N 2 A$ germline mutations predispose to the development of HNSCC. The proteins encoded by CDKN2A play critical roles in pathogenesis of HNSCC and LOH is likely a key early event. Our case is unique due to $\mathrm{p} 16$ positivity by IHC in the tumor. This finding does not necessarily represent HPV infection and when suspicious, should be confirmed by HPV genotyping by PCR. Furthermore, p16 positivity by IHC should not preclude familial HNSCC syndrome. Future studies should prospectively investigate the risk of HNSCC in those with a CDKN2A 
Table 3 Reports of selected neoplasms in association with germline CDKN2A mutation

\begin{tabular}{|c|c|c|}
\hline Type of cancer & References & Comments \\
\hline \multirow[t]{7}{*}{ Breast adenocarcinoma } & [29] & Standardized morbidity rate of $3.8(P=0.0014)$ \\
\hline & [30] & Case report \\
\hline & {$[31]$} & One pedigree described. Breast cancer in 5 members \\
\hline & [32] & 2 cases series of breast cancer \\
\hline & {$[34]$} & One pedigree described. Breast cancer in 1 member \\
\hline & [4] & Large registry study. Prevalence rate was 3.044 compared to CDKN2A wild type $(P<0.001)$ \\
\hline & [33] & One pedigree described. Breast cancer in proband \\
\hline \multirow[t]{3}{*}{ Lung cancer } & [33] & One pedigree described. Lung cancer in 3 members \\
\hline & [4] & Large registry study. Prevalence rate was 2.19 compared to CDKN2A wild type $(P<0.018)$ \\
\hline & [35] & Eight pedigrees described. Lung cancer in 6 members \\
\hline \multirow[t]{3}{*}{ Sarcoma } & [37] & Eight cases of sarcoma identified in melanoma -prone French families with CDKN2A germline mutation \\
\hline & [35] & Eight pedigrees described. Sarcoma in 5 members \\
\hline & [36] & $\begin{array}{l}744 \text { pediatric patients were screened for germline mutations: } 1 \text { patient with osteosarcoma found to } \\
\text { have CDKN2A germline mutation }\end{array}$ \\
\hline \multirow[t]{6}{*}{ Neurofibroma } & [39] & Case report \\
\hline & [22] & $\begin{array}{l}\text { In one pedigree, } 7 \text { members had neural system tumors including astrocytoma, neurofibroma, } \\
\text { schwanomma, and meningioma }\end{array}$ \\
\hline & [38] & One pedigree described. Neurofibroma in 4 members \\
\hline & [31] & One pedigree described. Neurofibroma in 3 members \\
\hline & [34] & One pedigree described. Neurofibroma in proband \\
\hline & [40] & One pedigree described. Neurofibroma in 3 members \\
\hline
\end{tabular}

germline mutation. It is important to consider CDKN2A mutation testing in familial HNSCC, even when p16 testing by IHC is positive, and patients with a CDKN2A mutation should be counseled regarding the potential increased risk of HNSCC. In addition, routine screening of HNSCC should be considered, patients should avoid known risk factors such as smoking and alcohol, and all patients should receive HPV vaccination.

\section{Conclusions}

We report a young female with no significant risk factors who developed tongue SCC. Family history revealed mother with oral SCC. Both the patient and her mother were found to have $C D K N 2 A$ c. $301 \mathrm{G}>\mathrm{T}$ germline mutation. $C D K N 2 A$ germline mutations may increase the risk of development of HNSCC and patients should be appropriately counseled and monitored for HNSCC.

\section{Patient perspectives}

"No one wants to hear that news that they have cancer. I had a pretty hard battle with multiple recurrences and multiple surgeries. When I came to UCSD I was on my third recurrence, feeling pretty discouraged. I have received excellent care from my current team of doctors. Adding genetic testing and counseling to my care provided some much-needed answers not only for me, but my family as well. I'm on my longest stretch of being disease free and am feeling well and thankful. Hopefully finding this link between the mutation and OSCC will help others in the future."

\section{Abbreviations}

CDK: Cyclin dependent kinase; CDKN2A: Cyclin dependent kinase inhibitor 2A; CT: Computed tomography; FAMMM: Familial atypical multiple mole melanoma; FNA: Fine needle aspiration; HNSCC: Head and neck squamous cell carcinoma; HPV: Human papilloma virus; IHC: Immunohistochemistry; NGS: Next generation sequencing; OSCC: Oral squamous cell cancers; PCR: Polymerase chain reaction; PET: Positron emission tomography; PTC: Papillary thyroid carcinoma; Rb: Retinoblastoma; SCC: Squamous cell carcinoma.

\section{Acknowledgements}

The authors thank the patients who participated in this research. This research was partially supported by the Altman Clinical \& Translational Research Institute (ACTRI) at the University of California, San Diego. The ACTRI is funded from awards issued by the National Center for Advancing Translational Sciences, NIH UL1TR001442. The content is solely the responsibility of the authors and does not necessarily represent the official views of the $\mathrm{NIH}$.

\section{Authors' contributions}

AJ wrote the manuscript and KF, RKO, and EEWC substantially revised the manuscript. All authors read and approved the final manuscript.

\section{Funding}

Not applicable.

Availability of data and materials

Not applicable. 


\section{Declarations}

\section{Ethics approval and consent to participate}

The need for ethics approval was waived and consent to participate was obtained.

\section{Consent for publication}

Consent for publication was obtained from the patient.

\section{Competing interests}

The authors declare that they have no competing interests.

\section{Author details}

'Division of Hematology and Oncology, Department of Medicine, University of California San Diego, 3855 Health Sciences Drive, La Jolla, CA 92093-0960, USA. ${ }^{2}$ Division of Otolaryngology, Department of Surgery, University of California San Diego, La Jolla, CA 92093, USA. ${ }^{3}$ Moores Cancer Center, University of California San Diego, La Jolla, CA 92093, USA

Received: 1 August 2021 Accepted: 2 January 2022

Published online: 05 February 2022

\section{References}

1. Robertson KD, Jones PA. Tissue-specific alternative splicing in the human INK4a/ARF cell cycle regulatory locus. Oncogene. 1999;18(26):3810-20.

2. Goldstein AM, Chan M, Harland M, Hayward NK, Demenais F, Bishop DT, et al. Features associated with germline CDKN2A mutations: a GenoMEL study of melanoma-prone families from three continents. J Med Genet. 2007:44(2):99-106.

3. Harinck F, Kluijt I, van der Stoep N, Oldenburg RA, Wagner A, Aalfs CM, et al. Indication for CDKN2A-mutation analysis in familial pancreatic cancer families without melanomas. J Med Genet. 2012;49(6):362-5.

4. Potrony M, Puig-Butillé JA, Aguilera P, Badenas C, Carrera C, Malvehy J, et al. Increased prevalence of lung, breast, and pancreatic cancers in addition to melanoma risk in families bearing the cyclin-dependent kinase inhibitor 2A mutation: implications for genetic counseling. J Am Acad Dermatol. 2014:71(5):888-95.

5. Ranade K, Hussussian CJ, Sikorski RS, Varmus HE, Goldstein AM, Tucker MA, et al. Mutations associated with familial melanoma impair p16INK4 function. Nat Genet. 1995;10(1):114-6.

6. Baker DJ, Childs BG, Durik M, Wijers ME, Sieben CJ, Zhong J, et al. Naturally occurring p16(Ink4a)-positive cells shorten healthy lifespan. Nature. 2016;530(7589):184-9.

7. Mountzios G, Rampias T, Psyrri A. The mutational spectrum of squamouscell carcinoma of the head and neck: targetable genetic events and clinical impact. Ann Oncol. 2014:25(10):1889-900.

8. Leemans CR, Snijders PJF, Brakenhoff RH. The molecular landscape of head and neck cancer. Nat Rev Cancer. 2018;18(5):269-82.

9. McLaughlin-Drubin ME, Crum CP, Münger K. Human papillomavirus E7 oncoprotein induces KDM6A and KDM6B histone demethylase expression and causes epigenetic reprogramming. Proc Natl Acad Sci USA. 2011;108(5):2130-5.

10. Fostira F, Koutsodontis G, Vagia E, Economopoulou P, Kotsantis I, Sasaki C, et al. Predisposing germline mutations in young patients with squamous cell cancer of the oral cavity. JCO Precis Oncol. 2018:2:1-8.

11. Oldenburg RA, de Vos tot Nederveen Cappel WH, van Puijenbroek $M$, van den Ouweland A, Bakker E, Griffioen G, et al. Extending the p16-Leiden tumour spectrum by respiratory tract tumours. J Med Genet. 2004:41(3):e31.

12. Schneider-Stock R, Giers A, Motsch C, Boltze C, Evert M, Freigang B, et al. Hereditary p16-Leiden mutation in a patient with multiple head and neck tumors. Am J Hum Genet. 2003;72(1):216-8.

13. Vinarsky V, Fine RL, Assaad A, Qian Y, Chabot JA, Su GH, et al. Head and neck squamous cell carcinoma in FAMMM syndrome. Head Neck 2009;31(11):1524-7

14. Yarbrough WG, Aprelikova O, Pei H, Olshan AF, Liu ET. Familial tumor syndrome associated with a germline nonfunctional p16INK4a allele. J Natl Cancer Inst. 1996:88(20):1489-91.
15. Yu KK, Zanation AM, Moss JR, Yarbrough WG. Familial head and neck cancer: molecular analysis of a new clinical entity. Laryngoscope. 2002;112(9):1587-93.

16. Ghiorzo P, Villaggio B, Sementa AR, Hansson J, Platz A, Nicoló G, et al. Expression and localization of mutant p16 proteins in melanocytic lesions from familial melanoma patients. Hum Pathol. 2004;35(1):25-33.

17. Walker GJ, Gabrielli BG, Castellano M, Hayward NK. Functional reassessment of P16 variants using a transfection-based assay. Int J Cancer. 1999:82(2):305-12.

18. Goldstein AM, Chan M, Harland M, Gillanders EM, Hayward NK, Avril MF, et al. High-risk melanoma susceptibility genes and pancreatic cancer, neural system tumors, and uveal melanoma across GenoMEL. Cancer Res. 2006;66(20):9818-28

19. Vasen H, Ibrahim I, Ponce CG, Slater EP, Matthäi E, Carrato A, et al. Benefit of surveillance for pancreatic cancer in high-risk individuals: outcome of long-term prospective follow-up studies from three european expert centers. J Clin Oncol. 2016;34(17):2010-9.

20. Soura E, Eliades PJ, Shannon K, Stratigos AJ, Tsao H. Hereditary melanoma: update on syndromes and management: genetics of familial atypical multiple mole melanoma syndrome. J Am Acad Dermatol. 2016;74(3):395-407.

21. Aslanian HR, Lee JH, Canto MI. AGA clinical practice update on pancreas cancer screening in high-risk individuals: expert review. Gastroenterology. 2020;159(1):358-62.

22. Bahuau M, Vidaud D, Jenkins RB, Bièche I, Kimmel DW, Assouline B, et al. Germ-line deletion involving the INK4 locus in familial proneness to melanoma and nervous system tumors. Cancer Res. 1998:58(11):2298-303.

23. Cabanillas R, Astudillo A, Valle M, de la Rosa J, Álvarez R, Durán NS, et al. Novel germline CDKN2A mutation associated with head and neck squamous cell carcinomas and melanomas. Head Neck. 2013;35(3):E80-4.

24. Della Torre G, Pasini B, Frigerio S, Donghi R, Rovini D, Delia D, et al. CDKN2A and CDK4 mutation analysis in Italian melanoma-prone families: functional characterization of a novel CDKN2A germ line mutation. $\mathrm{Br} J$ Cancer. 2001;85(6):836-44.

25. Sun S, Pollock PM, Liu L, Karimi S, Jothy S, Milner BJ, et al. CDKN2A mutation in a non-FAMMM kindred with cancers at multiple sites results in a functionally abnormal protein. Int J Cancer. 1997;73(4):531-6.

26. Whelan AJ, Bartsch D, Goodfellow PJ. Brief report: a familial syndrome of pancreatic cancer and melanoma with a mutation in the CDKN2 tumorsuppressor gene. N Engl J Med. 1995;333(15):975-7.

27. Chan SH, Lim WK, Michalski ST, Lim JQ, Ishak NDB, Met-Domestici M, et al. Germline hemizygous deletion of CDKN2A-CDKN2B locus in a patient presenting with Li-Fraumeni syndrome. NPJ Genom Med. 2016;1:16015.

28. Goldstein AM, Stacey SN, Olafsson JH, Jonsson GF, Helgason A, Sulem P, et al. CDKN2A mutations and melanoma risk in the Icelandic population. J Med Genet. 2008;45(5):284-9.

29. Borg A, Sandberg T, Nilsson K, Johannsson O, Klinker M, Måsbäck A, et al. High frequency of multiple melanomas and breast and pancreas carcinomas in CDKN2A mutation-positive melanoma families. J Natl Cancer Inst 2000;92(15):1260-6.

30. Hewitt C, Lee WuC, Evans G, Howell A, Elles RG, Jordan R, et al. Germline mutation of ARF in a melanoma kindred. Hum Mol Genet. 2002:11(11):1273-9.

31. Prowse AH, Schultz DC, Guo S, Vanderveer L, Dangel J, Bove B, et al. Identification of a splice acceptor site mutation in p16INK4A/p14ARF within a breast cancer, melanoma, neurofibroma prone kindred. J Med Genet. 2003;40(8):e102.

32. Monnerat C, Chompret A, Kannengiesser C, Avril MF, Janin N, Spatz $A$, et al. BRCA1, BRCA2, TP53, and CDKN2A germline mutations in patients with breast cancer and cutaneous melanoma. Fam Cancer. 2007;6(4):453-61

33. Shah V, Boyd KD, Houlston RS, Kaiser MF. Constitutional mutation in CDKN2A is associated with long term survivorship in multiple myeloma: a case report. BMC Cancer. 2017:17(1):718.

34. Vanneste R, Smith E, Graham G. Multiple neurofibromas as the presenting feature of familial atypical multiple malignant melanoma (FAMMM) syndrome. Am J Med Genet A. 2013;161a(6):1425-31.

35. Lynch HT, Brand RE, Hogg D, Deters CA, Fusaro RM, Lynch JF, et al. Phenotypic variation in eight extended CDKN2A germline mutation familial atypical multiple mole melanoma-pancreatic carcinoma-prone families: 
the familial atypical mole melanoma-pancreatic carcinoma syndrome. Cancer. 2002;94(1):84-96.

36. Fiala EM, Jayakumaran G, Mauguen A, Kennedy JA, Bouvier N, Kemel Y, et al. Prospective pan-cancer germline testing using MSK-IMPACT informs clinical translation in 751 patients with pediatric solid tumors. Nat Cancer. 2021;2:357-65.

37. Jouenne F, ChauvotdeBeauchene I, Bollaert E, Avril MF, Caron O, Ingster $\mathrm{O}$, et al. Germline CDKN2A/P16INK4A mutations contribute to genetic determinism of sarcoma. J Med Genet. 2017:54(9):607-12.

38. Petronzelli F, Sollima D, Coppola G, Martini-Neri ME, Neri G, Genuardi M. CDKN2A germline splicing mutation affecting both p16(ink4) and p14(arf) RNA processing in a melanoma/neurofibroma kindred. Genes Chromosomes Cancer. 2001;31(4):398-401.

39. Petty EM, Gibson LH, Fountain JW, Bolognia JL, Yang-Feng TL, Housman $D E$, et al. Molecular definition of a chromosome 9 p21 germ-line deletion in a woman with multiple melanomas and a plexiform neurofibroma: implications for $9 p$ tumor-suppressor gene(s). Am J Hum Genet. 1993;53(1):96-104.

40. Sargen MR, Merrill SL, Chu EY, Nathanson KL. CDKN2A mutations with p14 loss predisposing to multiple nerve sheath tumours, melanoma, dysplastic naevi and internal malignancies: a case series and review of the literature. Br J Dermatol. 2016;175(4):785-9.

\section{Publisher's Note}

Springer Nature remains neutral with regard to jurisdictional claims in published maps and institutional affiliations.

- fast, convenient online submission

- thorough peer review by experienced researchers in your field

- rapid publication on acceptance

- support for research data, including large and complex data types

- gold Open Access which fosters wider collaboration and increased citations

- maximum visibility for your research: over $100 \mathrm{M}$ website views per year

At BMC, research is always in progress.

Learn more biomedcentral.com/submissions 